\title{
Tighter nanotech regulations touted
}

The Canadian government is about to introduce the first mandatory programme in the world for reporting the safety of manufactured nanomaterials.

The scheme will require companies to provide any details that they have about the physical, chemical and toxicological properties of nanomaterials they make or import in quantities greater than one kilogram.

The government agencies Environment Canada and Health Canada will use the data to make risk assessments for the materials and to establish more specific regulations.

In 2007, the government asked the Council of Canadian Academies to assess the state of health and safety in nanotechnology. The council's panel of experts, chaired by physicist Pekka Sinervo from the University of Toronto in Ontario, reported in July 2008 that very little information existed about the risks associated with nanomaterials. "There is an urgency to come to grips with this issue," says Sinervo.
But he cautions that the success of the scheme will rely on how well the Canadian approach integrates with its main trading partners in other nations.

Voluntary data-reporting schemes have been trialled in other countries with limited success. The ongoing voluntary programme of the US Environmental Protection Agency (EPA) has so far received submissions from 29 companies on more than 120 nanoscale materials; only four companies have submitted any more than basic physical and chemical information. There has been "very little participation", says Colin Finan, from the Project on Emerging Nanotechnologies, based at the Woodrow Wilson International Center for Scholars in Washington DC.

The UK Department for Environment, Food and Rural Affairs (DEFRA) ran a twoyear voluntary reporting programme from September 2006, which received 11 submissions. Across Europe, REACH (Registration,
Evaluation, Authorisation and Restriction of Chemical substances) regulations are currently being reviewed to clarify how nanomaterials are dealt with.

Anne Mitchell, executive director of the Canadian Institute for Environmental Law and Policy in Toronto, expects a mandatory scheme to work more effectively than voluntary programmes, and is pleased that companies are expected to provide their data within four months of beginning to use or supply a nanomaterial.

Finan expects the United States, and perhaps other countries, to follow Canada's lead. “The EPA all but said they're going to issue regulations," he says. "Once one country starts doing something, many other countries start doing the same."

"It's going to be a useful process for the rest of the world to learn from," says Steve Morgan, nanotechnologies policy adviser at DEFRA. "We're all watching with interest."

Katharine Sanderson 